\title{
Development of microsatellite markers for the small yellow croaker Larimichthys polyactis (Sciaenidae) by cross-species amplification
}

\author{
D.Q. Sun, H.Y. Li, T.J. Xu and R.X. Wang \\ Key Laboratory for Marine Living Resources and Molecular Engineering, \\ College of Marine Science, Zhejiang Ocean University, Zhoushan, P.R. China \\ Corresponding author: T.J. Xu / R.X. Wang \\ E-mail: tianjunxu@163.com / wangrixin1123@126.com
}

Genet. Mol. Res. 11 (2): 1469-1474 (2012)

Received March 2, 2011

Accepted September 11, 2011

Published May 21, 2012

DOI http://dx.doi.org/10.4238/2012.May.21.3

\begin{abstract}
The small yellow croaker (Larimichthys polyactis) is a highly valued fish for human consumption found in the Western Pacific that was considered endangered until recently because of overfishing. We selected microsatellite markers for this species from markers developed for Miichthys miiuy, also of the family Sciaenidae. Among 43 markers polymorphic for M. miiuy, 11 were found to be polymorphic for L. polyactis. Characterization of these 11 loci was made based on $30 \mathrm{~L}$. polyactis individuals collected by trawling in the Zhoushan Fishing Ground, Zhejiang Province, China. Total genomic DNA was isolated from fin clips. The number of alleles per locus ranged from 4 to 10 , with a mean of 5.82, while the effective number of alleles ranged from 1.64 to 10.00 , with a mean of 3.22. Observed and expected heterozygosities ranged from 0.17 to 0.72 and from 0.39 to 0.81 , respectively. Significant deviation from Hardy-Weinberg equilibrium was found at four loci, after applying Bonferroni's correction. There was no significant association between any of the pairs of microsatellite loci, hence allelic variation at these loci was considered independent. These 11 polymorphic microsatellite loci
\end{abstract}


will be useful for genetic diversity analysis and molecular-assisted breeding for L. polyactis.

Key words: Larimichthys polyactis; Cross-species amplification; Microsatellite loci

\section{INTRODUCTION}

The small yellow croaker, Larimichthys polyactis (Bleeker) is a benthopelagic fish species of the family Sciaenidae, living in warm-temperate sea water (Lin et al., 2004). Extensively distributed in the Yellow Sea and the East China Sea of the Northwest Pacific Ocean (Froese and Pauly, 2011), the small yellow croaker has been considered an important fishery resource and important marine food fish species in Asian countries because of its wide distribution and high capture production. In 2000, the global landing of small yellow croaker reached 320 thousand metric tons (Seikai National Fisheries Research Institute, 2001), but on the other hand, overfishing will have a negative effect on the resource of the small yellow croaker. There is evidence demonstrating that the resource of small yellow croaker has sharply decreased under the effect of over-exploitation in the past decades (Jin, 2004; Lin et al., 2008). Thus, L. polyactis has recently been the target of conservation concern.

Intensive studies focused on the areas of catch statistics, size compositions, early life history, and feeding habits (Xue et al., 2004; Wan and Sun, 2006; Yan et al., 2006). Although several studies have been conducted to investigate the genetic characteristics of the small yellow croaker by using molecular markers in recent years (Meng et al., 2003; Lin et al., 2009; Xiao et al., 2009), the information is still limited. Lack of enough polymorphic molecular markers limited the development of molecular phylogeny, population structure and conservation genetics in this species.

Microsatellites or simple sequence repeats (SSRs) of two to six nucleotides in a tandem repeat pattern are abundant and spread throughout the eukaryotic genome. They are recognized as powerful and informative genetic markers in molecular genetic studies, such as genetic mapping, population genetics, and marker-assisted selection, since they are codominant and highly polymorphic even within populations, and show stable amplification by polymerase chain reaction (PCR) (Morgante and Olivieri, 1993; Byrne et al., 1996; Oliveira et al., 2006). Unusually high mutation rates for the nucleotide sequences result in a high level of polymorphism for microsatellite markers (Peakall et al., 1998). However, microsatellite development for each target species requires sequence information from DNA regions flanking the repeat motif to design primers, which is generally time-consuming and requires the investment of resources on the part of the researchers.

The DNA sequences flanking SSRs are generally conserved within individuals of the same species allowing the selection of PCR primers that will amplify the intervening microsatellite in all genotypes. Thus, using loci already developed in a related species may provide a cost-effective alternative to microsatellite isolation and development. Rico et al. (1996) examined the conservation of microsatellite regions across distantly related species using 18 microsatellite loci isolated from other fish species to test across diverse fish species of 470 million years, and they revealed a high level of conservation of the flanking and microsatellite sequences. Cross-amplification has been studied to exploit microsatellite loci in phylogeneti- 
cally related species (Moore et al., 1991; Pepin et al., 1995; Engel et al., 1996; Kuhn et al., 1996; Wilson et al., 1997; Slate et al., 1998). Generally, the number of loci amplified tends to decrease with increasing divergence between species (Moore et al., 1991; Peakall et al., 1998). Wilson et al. (2004) found that the success of cross-amplification in species belonging to the same genus as the target species is high.

We have already isolated and characterized polymorphic microsatellite marker in Miichthys miiuy, derived from genomic DNA marker (Wang et al., 2010) and an expressed sequence tag (EST) library (Xu et al., 2011). Liu et al. (2006) reported the availability of microsatellite markers developed from an EST library of the olive flounder for other marine fishes. M. miiuy and L. polyactis both belong to the same fish species of the family Sciaenidae. In the present study, we attempted to develop microsatellites of the small yellow croaker using cross-amplification.

\section{MATERIAL AND METHODS}

\section{Fish sample and DNA extraction}

L. polyactis individuals were collected by trawling in the Zhoushan Fishing Ground, Zhejiang Province, China. They were identified by morphology. Fin clips were removed and immediately preserved in alcohol at $-20^{\circ} \mathrm{C}$. Total genomic DNA was isolated from the fin clips using the standard phenol-chloroform method with some modifications and subsequently dissolved in $100 \mu \mathrm{L} \mathrm{ddH}_{2} \mathrm{O}$. The quality and concentration of DNA were detected on agarose gel electrophoresis and GeneQuant pro RNA/DNA spectrophotometer. DNA were finally adjusted to $100 \mathrm{ng} / \mu \mathrm{L}$ and stored at $-20^{\circ} \mathrm{C}$ for using.

\section{PCR amplification and polymorphism screened}

Forty-three loci of microsatellite markers developed in genomic DNA and EST library of M. miiuy were cross-amplified in DNA samples from L. polyactis. PCR was performed in a $15-\mu \mathrm{L}$ reaction mixture containing $1 \mathrm{X}$ PCR buffer, $1.2 \mu \mathrm{L}$ dNTPs, $0.4 \mu \mathrm{L}$ forward and reverse primers, and $0.3 \mu \mathrm{L} \mathrm{Taq}$ polymerase $\left(5 \mathrm{U} / \mu \mathrm{L}\right.$; Tiangen). The cycling conditions were $95^{\circ} \mathrm{C}$ for $5 \mathrm{~min}$ followed by 30 cycles of $95^{\circ} \mathrm{C}$ for $30 \mathrm{~s}$, annealing for $30 \mathrm{~s}$, and extension for $30 \mathrm{~s}$ at $72^{\circ} \mathrm{C}$, finally followed with post-cycling extension for $5 \mathrm{~min}$ at $72^{\circ} \mathrm{C}$, and then holding at $4^{\circ} \mathrm{C}$. PCR amplification was performed on a BIO-RAD S1000 ${ }^{\mathrm{TM}}$ thermal cycler.

Polymorphism at each locus was performed by PCR based on genomic DNA of 30 samples. The products of PCR amplifications were confirmed by $1.5 \%$ agarose gel electrophoresis and then denatured at $96^{\circ} \mathrm{C}$ for 8 min using denaturant $(98 \%$ formamide, $10 \mathrm{mM}$ EDTA, $0.25 \% \mathrm{FF}$ ). The denatured amplified products were separated on $6 \%$ denaturing polyacrylamide gels using silver staining. A denatured pBR322 DNA/MspI molecular weight marker (Tiangen) was used as a size standard to identify alleles.

\section{Polymorphism analysis}

Genotypes were determined as approximate allele size (bp). Number of alleles per locus $\left(N_{\mathrm{A}}\right)$, effective number of alleles $\left(N_{\mathrm{E}}\right)$, expected $\left(H_{\mathrm{E}}\right)$ and observed $\left(H_{\mathrm{O}}\right)$ heterozygosities, 
and Hardy-Weinberg equilibrium (HWE) were examined using a POPGENE software package (Yeh and Boyle, 1997). $N_{\mathrm{E}}$ was estimated based on the formula: $N_{\mathrm{E}}=1 / \sum \mathrm{xi}^{2}$, where xi is the frequency of the $i$ th allele for each locus (Crow and Kimura, 1965). The ARLEQUIN 3.11 software was used to calculate genotypic linkage disequilibrium between these loci (Schneider et al., 2000). All results for multiple tests were adjusted using Bonferroni's correction (Rice, 1989).

\section{RESULTS AND DISCUSSION}

By the method of cross-species amplification, all of the 43 markers of M. miiuy were successfully amplified in the small yellow croaker except four pairs of primers. Further characterization of these markers in the small yellow croaker was tested based on 30 individuals. Among these 39 pairs of amplified primers, 11 loci were polymorphic for L. polyactis and the details of these loci in the small yellow croaker are listed in Table $1 . N_{\mathrm{A}}$ per locus for the small yellow croaker ranged from 4 to 10 , with an average of 5.82, while $N_{\mathrm{E}}$ ranged from 1.64 to 10.00 with an average of 3.22 . $H_{\mathrm{O}}$ and $H_{\mathrm{E}}$ ranged from 0.17 to 0.72 and from 0.39 to 0.81 , respectively. Significant deviation from HWE was found at Mimi-15, Mimi-43-H04, Mimi54-D06, and Mimi-57-A05 after Bonferroni's correction ( $\mathrm{P}<0.0045$, adjusted value). There was no significant association between any pair of microsatellite loci, and hence, allelic variation at these loci was considered to be independent.

In our study, the size of alleles for some loci in the small yellow croaker showed nonconformity with M. miiuy. Several authors have reported intraspecific and interspecific allelic size variation at microsatellite loci, which was caused by insertions and deletions (indels) in the flanking regions (Angers and Bernatchez, 1997; Grimaldi and Crouau-Roy, 1997; Colson and Goldstein, 1999; Matsuoka et al., 2002). In all, these polymorphic microsatellite loci will be useful for genetic diversity analysis and molecular-assisted breeding for L. polyactis. The microsatellite markers from M. miiuy were available to develop microsatellite loci for other Sciaenidae species by the method of cross-species amplification, which is truly effective.

\section{Table 1. Characteristics of 11 polymorphic microsatellite loci in small yellow croaker.}

\begin{tabular}{|c|c|c|c|c|c|c|c|c|c|}
\hline Locus & GenBank accession No. & Repeat motif & $\operatorname{Tm}\left({ }^{\circ} \mathrm{C}\right)$ & Size range (bp) & $N_{\mathrm{A}}$ & $N_{\mathrm{E}}$ & $H_{\mathrm{O}}$ & $H_{\mathrm{E}}$ & $\operatorname{HWE}(\mathrm{P})$ \\
\hline Mimi-3 & GU084248 & $(\mathrm{CA})_{9}$ & 48 & $170-188$ & 6 & 3.20 & 0.63 & 0.69 & 0.068 \\
\hline Mimi-6 & GU084250 & $(\mathrm{CA})_{23}$ & 50 & $174-184$ & 5 & 5.00 & 0.40 & 0.64 & 0.103 \\
\hline Mimi-15 & GU084252 & $(\mathrm{CA})_{15}$ & 49 & $120-128$ & 4 & 1.64 & 0.32 & 0.39 & $0.001 *$ \\
\hline Mimi-16-A03 & GW668869 & $(\mathrm{T})_{15}$ & 50 & $289-301$ & 6 & 4.44 & 0.70 & 0.78 & 0.121 \\
\hline Mimi-28-G08 & GW669768 & $(\mathrm{A})_{14}$ & 47 & $242-249$ & 6 & 6.00 & 0.70 & 0.81 & 0.009 \\
\hline Mimi-34-A09 & GW670103 & (A) 13 & 50 & $112-119$ & 7 & 7.00 & 0.72 & 0.78 & 0.499 \\
\hline Mimi-35-E08 & GW670215 & $(\mathrm{T})_{12}^{13}$ & 51 & $139-162$ & 7 & 7.00 & 0.67 & 0.62 & 0.998 \\
\hline Mimi-40-H12 & GW670618 & $(\mathrm{CCT})_{5}$ & 47 & $218-233$ & 5 & 5.00 & 0.45 & 0.65 & 0.123 \\
\hline Mimi-43-H04 & GW670839 & $($ TTTC) 6 & 50 & $133-197$ & 10 & 10.00 & 0.67 & 0.73 & $0.000 *$ \\
\hline Mimi-54-D06 & GW671567 & $(\mathrm{T})_{13} \ldots(\mathrm{A})_{15}$ & 50 & $163-173$ & 4 & 4.00 & 0.17 & 0.54 & $0.000 *$ \\
\hline Mimi-57-A05 & GW671772 & $(\mathrm{T})_{14}$ & 50 & $174-184$ & 4 & 4.00 & 0.26 & 0.55 & $0.003^{*}$ \\
\hline Average & & & & & 5.82 & 3.22 & 0.52 & 0.65 & \\
\hline
\end{tabular}

Tm $=$ melting temperature; $N_{\mathrm{A}}=$ number of alleles; $N_{\mathrm{E}}=$ effective number of alleles; $H_{\mathrm{E}}$ and $H_{\mathrm{O}}=$ expected and observed heterozygosities, respectively; HWE $=$ Hardy-Weinberg equilibrium. $*$ Significant deviation from HWE $(\mathrm{P}<0.0045$, Bonferroni, adjusted value $)$. 


\section{ACKNOWLEDGMENTS}

Research supported by the National Nature Science Foundation of China (\#31001120) and the Zhejiang Provincial Natural Science Foundation of China (\#Y3100013).

\section{REFERENCES}

Angers B and Bernatchez L (1997). Complex evolution of a salmonid microsatellite locus and its consequences in inferring allelic divergence from size information. Mol. Biol. Evol. 14: 230-238.

Byrne M, Marquez-Garcia MI, Uren T and Smith DS (1996). Conservation and genetic diversity of microsatellite loci in the genus Eucalyptus. Aust. J. Bot. 44: 331-341.

Colson I and Goldstein DB (1999). Evidence for complex mutations at microsatellite loci in Drosophila. Genetics 152: $617-627$

Crow JF and Kimura M (1965). Evolution in sexual and asexual populations. Am. Nat. 99: 439-450.

Engel SR, Linn RA, Taylor JF and Davis SK (1996). Conservation of microsatellite loci across species of Artiodactyls: implications for population studies. J. Mammal. 77: 504-518.

Froese R and Pauly D (2011). FishBase. World Wide Web Electronic Publication. Available at [www.fishbase.org].

Grimaldi MC and Crouau-Roy B (1997). Microsatellite allelic homoplasy due to variable flanking sequences. J. Mol. Evol. 44: $336-340$

Jin X (2004). Long-term changes in fish community structure in the Bohai Sea, China. Estuar. Coast. Shelf Sci. 59: 163-171.

Kuhn R, Anastassiadis C and Pirchner F (1996). Transfer of bovine microsatellites to the cervine (Cervus elaphus). Anim. Genet. 27: 199-201.

Lin LS, Cheng JH and Ren YP (2004). Analysis of population biology of small yellow croaker Pseudosciaena polyactis in the East China Sea region. J. Fish Sci. China 11: 338.

Lin LS, Chen JH and Li HY (2008). The fishery biology of Trichiurus japonicus and Larimichthys polyactis in the East China Sea region. Mar. Fish. 30: 126-134.

Lin LS, Ying YP, Han ZQ and Xiao SY (2009). AFLP analysis on genetic diversity and population structure of small yellow croaker Larimichthys polyactis. Afr. J. Biotechnol. 8: 2700-2706.

Liu YG, Zheng MG, Liu LX and Lin H (2006). Five new microsatellite loci for Oliver flounder (Paralichthys olivaceus) from an expressed sequence tag (EST) library and cross-species amplification. Mol. Ecol. Note 6: 371-373.

Matsuoka Y, Mitchell SE, Kresovich S, Goodman M, et al. (2002). Microsatellites in Zea - variability, patterns of mutations, and use for evolutionary studies. Theor. Appl. Genet. 104: 436-450.

Meng ZN, Zhuang ZM, Jin XS and Tang QS (2003). Genetic diversity in small yellow croaker (Pseudosciaena polyactis) by RAPD analysis. Biodivers. Sci. 11: 197-203.

Moore SS, Sargeant LL, King TJ and Mattick JS (1991). The consideration of dinucleotide microsatellite among mammalian genomes allows the use of heterologous PCR primer pairs in closely related species. Genomics 10 : 654-660.

Morgante M and Olivieri AM (1993). PCR-amplified microsatellites as markers in plant genetics. Plant J. 3: 175-182.

Oliveira EJ, Pádua JG, Zucchi MI, Vencovsky R, et al. (2006). Origin, evolution and genome distribution of microsatellites. Genet. Mol. Biol. 29: 294-307.

Peakall R, Gilmore S, Keys W, Morgante M, et al. (1998). Cross-species amplification of soybean (Glycine max) simple sequence repeats (SSRs) within the genus and other legume genera: implications for the transferability of SSRs in plants. Mol. Biol. Evol. 15: 1275-1287.

Pepin L, Amigues Y, Lepingle A, Berthier JL, et al. (1995). Sequence conservation of microsatellites between Bos taurus (cattle), Capra hircus (goat) and related species. Examples of use in parentage testing and phylogeny analysis. Heredity 74: 53-61.

Rice WE (1989). Analyzing tables of statistical tests. Evolution 43: 223-225.

Rico C, Rico I and Hewitt G (1996). 470 million years of conservation of microsatellite loci among fish species. Proc. Biol. Sci. 263: 549-557.

Schneider S, Roessli D and Excoffier L (2000). ARLEQUIN: A Software for Population Genetics Data Analysis, Version 2.000. Genetics and Biometry Laboratory, Department of Anthropology. University of Geneva, Geneva.

Seikai National Fisheries Research Institute (2001). Biological and Ecological Characteristics of Valuable Fisheries Resources from the East China Sea and the Yellow Sea, Comparison Between the Chinese and Japanese Knowledges. Seikai National Fisheries Research Institute, Nagasaki. 
Slate J, Coltman DW, Goodman SJ, MacLean I, et al. (1998). Bovine microsatellite loci are highly conserved in red deer (Cervus elaphus), sika deer (Cervus nippon) and Soay sheep (Ovis aries). Anim. Genet. 29: 307-315.

Wan RJ and Sun S (2006). The category composition and abundance of ichthyoplankton in the ecosystem of the Yellow Sea and the East China Sea. Acta Zool. Sin. 52: 28-44.

Wang RX, Xu TJ, Sun YN and He GY (2010). Polymorphic microsatellite loci from two enriched genomic libraries for the genetic analysis of the miiuy croaker, Miichthys miiuy (Sciaenidae). Genet. Mol. Res. 9: 931-934.

Wilson ACC, Massonnet B, Simon JC, Leterme NP, et al. (2004). Cross-species amplification of microsatellite loci in aphids: assessment and application. Mol. Ecol. Notes 4: 104-109.

Wilson GA, Strobeck C, Wu L and Coffin JW (1997). Characterization of microsatellite loci in caribou Rangifer tarandus, and their use in other artiodactyls. Mol. Ecol. 6: 697-699.

Xiao Y, Zhang Y, Gao T, Takashi Y, et al. (2009). Genetic diversity in the mtDNA control region and population structure in the small yellow croaker Larimichthys polyactis. Environ. Biol. Fish. 85: 303-314.

Xu T, Sun D, Sun Y and Wang R (2011). Development of 30 novel polymorphic expressed eequence tags (EST)-derived microsatellite markers for the Miiuy Croaker, Miichthys miiuy. Int. J. Mol. Sci. 12: 4021-4026.

Xue Y, Jin XS, Zhang B and Liang ZL (2004). Diet composition and seasonal variation in feeding habits of small yellow croaker Pseudosciaena polyactis Bleeker in the central Yellow Sea. J. Fish. Sci. China 3: 237-243.

Yan LP, Hu F, Ling JZ and Li SF (2006). Study on age and growth of Larimichthys polyactis in the East China Sea. Period. Ocean Univ. China 36: 95-100.

Yeh FC and Boyle TJB (1997). Population genetic analysis of co-dominant and dominant markers and quantitative traits. Belgian J. Bot. 129: 157. 